\title{
Microbial Production of Xylitol from D-arabitol by Gluconobacter Oxydans
}

\author{
Huanhuan ZHANG \\ School of Food \& Biological Engineering \\ Jiangsu University \\ Zhenjiang, China \\ e-mail: qxh@ujs.edu.cn \\ Tinashe Archbold MAGOCHA \\ School of Food \& Biological Engineering \\ Jiangsu University \\ Zhenjiang, China \\ e-mail: qxh@ujs.edu.cn \\ Yanbo XUE \\ School of Food \& Biological Engineering \\ Jiangsu University \\ Zhenjiang, China \\ e-mail: qxh@ujs.edu.cn
}

\author{
Junhua YUN \\ School of Food \& Biological Engineering \\ Jiangsu University \\ Zhenjiang, China \\ e-mail: qxh@ujs.edu.cn \\ Miaomiao YANG \\ School of Food \& Biological Engineering \\ Jiangsu University \\ Zhenjiang, China \\ e-mail: qxh@ujs.edu.cn \\ Xianghui QI* \\ School of Food \& Biological Engineering \\ Jiangsu University \\ Zhenjiang, China \\ e-mail: qxh@ujs.edu.cn
}

\begin{abstract}
Xylitol, a five carbon sugar alcohol, has numerous applications in the fields of food and pharmaceuticals. Gluconobacter oxydans contains two enzymes which are membrane-bound D-arabitol dehydrogenase and soluble xylitol dehydrogenase enabling the production of xylitol from D-arabitol. This review provides comprehensive insights regarding properties of key enzymes and advances of xylitol production of $G$. oxydans by microbial methods.
\end{abstract}

Keywords-Gluconobacter oxydans; xylitol; D-arabitol dehydrogenase; xylitol dehydrogenase

\section{INTRODUCTION}

Xylitol, a five-carbon sugar-alcohol, widely exists in fruits and vegetables and some other plants. Since its sweetness is similar to sucrose, it is used as an alternative to natural sweeteners [1.2]. Xylitol is also used as a sugar substitute by for diabetic patients. In addition, xylitol is reported to play a role in preventing dental caries. Because of its negative heat of dissolution, it offers a fresh and cooling in the oral cavity [3.4]. Therefore, the method of producing xylitol has caused extensive attention.

Though xylitol extensively exists in fruit and vegetables, it is difficult and costly to extract from natural objects directly for its content is relatively low. At present, large-scale production is typically obtained by a chemical process of D-xylose hydrogenation [5]. However, due to too many steps involved in this process, it costs a lot and had a negative impact on the environment. So the biotransformation method has aroused researcher's attention.

Traditional biological method for production of xylitol cannot transform glucose to xylitol directly. And until now, there have no any microbe can transform glucose to xylitol directly in the nature. G.oxydans can produce xylitol from D-arabitol based on two simple steps including two key enzymes ( $\mathrm{ArDH}$ and $\mathrm{XDH}$ ) in the metabolic pathway. This review introduces the research of xylitol production from D-arabitol by $G$. oxydan based on the special mechanisms, and the biotransformation process of D-arablitol to xylitol, and some achievements of microbial production of xylitol from D-arabitol by G.oxydans.

\section{BIOSYNTHETIC PATHWAY AND MICROORGANISM INVOLVING XYLITOL PRODUCTION}

\section{A. Three-step Fermentation Process.}

In 1969, Onishi and Suzuki [6] put forward a three-step process for bioconversion of glucose to xylitol firstly. (Fig.1). The first step, completed the conversion of D-glucose to D-arabitol with Debaryomyces hansenii; for the second step, Acetobacter suboxydans was took charge of biotransformation from D-arabitol to D-xylulose; for the third step, Candida guilliermondii answered for the biotransformation from D-xylulose to xylitol. The three procedures, last $211 \mathrm{~h}$ and the final yield obtained from D-glucose was $11 \%$. Due to the low yield productivity, people found the procedure to be less effective and gave up it.



Figure 1. Three-step fermentation process from D-glucose to xylitol 


\section{B. Two-step Fermentation Process}

Suzuki [7] screened a G. oxydans strain which can shorten the three-step process. For first procedure, Debaryomyces hansenii was responsible for biotransformation from D-glucose to D-arabitol, for second procedure, G. oxydans consumed D-xylulose to xylitol (Fig. 2). The G. oxydans possess two enzymes enabling the production of xylitol from $\mathrm{D}$-arabitol. The two enzymes are the membrane-bound D-arabitol dehydrogenase $(\mathrm{ArDH})$ and the soluble NADP-dependent xylitol dehydrogenase (XDH).

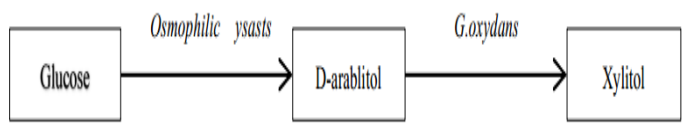

Figure 2. Two-step fermentation process

\section{D-ARABitol Dehydrogenase AND XYLitol DEHYDROGENASE}

The transformation from D-arabitol to xylitol is realized by G.oxydans because of its membrane-bound $\mathrm{ArDH}$ and soluble NAD-dependent $\mathrm{XDH}$. This process involves oxidation of D-arabitol to D-xylulose by D-arabitol dehydrogenase $(\mathrm{AraDH})$, followed by reduction of the D-xylulose to xylitol by xylitol dehydrogenase (XDH) (Fig. 3) [8].



Figure 3. Schematic representation of xylitol production from D-arabitol

\section{A. Properties of $\mathrm{ArDH}$}

ArDH is a kind of polyhydric alcohol dehydrogenase, plays a great role in the pentose metabolism process. ArDH is part of the short-chain dehydrogenase family and its subunit is composed of 250 300 amino acids residues, in which only 20 amino acid residues were highly conserved [9]. Hairong Cheng [9] cloned the D-arabitol dehydrogenase gene from $G$. oxydans and demonstrated the optimum $\mathrm{pH}$ of polyols oxidation with ArDH was around 8.5 in Tris-Cl buffer, while the optimum $\mathrm{pH}$ of reductive sugar reduction was 6.5 . Adachi $\mathrm{O}[10]$ investigated the membrane-bound quinoprotein D-Arabitol dehydrogenase of G. suboxydans IFO 3257, in which the optimal $\mathrm{pH}$ of $\mathrm{D}$-arabitol oxidation with $\mathrm{ArDH}$ was at 5.0. According to relevant researches, the optimum $\mathrm{pH}$ of oxidation D-arabitol into D-xylulose is pH5.0 6.0 [11].

\section{B. Properties of $X D H$}

$\mathrm{XDH}$ is an oxidordeuctase, which catalytic activity is reversible. Xylulose is reduced to xylitol using NADH as coenzyme, while xylitol is oxidized to xylulose using $\mathrm{NAD}^{+}$ as coenzyme [12]. In this paper, we describe the characterization of XDH from G. oxydans. The $x d h$ from G.oxydans was investigated by Masakazu [12]. The optimal $\mathrm{pH}$ of $\mathrm{XDH}$ oxidation for xylitol in the presence of $\mathrm{NAD}^{+}$ was around $\mathrm{pH} 11.0$, while that of reduction for $\mathrm{D}$-xylulose was around $\mathrm{pH}$ 5.0. Shen's [13] research got the same information. It implies that the optimal $\mathrm{pH}$ value of $\mathrm{XDH}$ oxidation is usually within the range of alkalinity, while that of reduction reaction usually in the range of acidity.

\section{BIOTRANSFORMATION OF XYLITOL FROM D-ARABITOL}

The enzyme activity and coenzyme regeneration efficiency were increased in the recombinant $G$. oxydans strains compared to wild type of G.oxydans, so as to achieve efficient conversion of D-arabitol and obtained the high yield of xylitol. Sha Li et al [14] made Glucose-6-phosphate dehydrogenase (G-6-PDH) and 6-phosphogluconate dehydrogenase (6-PGDH) overexpressed in G. oxydans. The xylitol productivity $\left(0.62 \mathrm{~g} \cdot \mathrm{L}^{-1} / \mathrm{h}\right)$ of the recombinant $G$. oxydans strain was 3.26-fold of the wild type strain (0.19 $\left.\mathrm{g} \cdot \mathrm{L}^{-1} / \mathrm{h}\right)$. The $G$. oxydans $\mathrm{PZ}$ strain produced $29.3 \mathrm{~g} \cdot \mathrm{L}^{-1}$ xylitol from $40 \mathrm{~g} \cdot \mathrm{L}^{-1}$ D-arabitol. Zhang et al [15] constructed a recombinant strain of $G$. oxydans PXPG to coexpress the $\mathrm{XDH}$ gene and a cofactor regeneration enzyme (glucose dehydrogenase, GDH) gene from Bacillus subtilis. The results showed that $G$. oxydans PXPG can produce $12.23 \mathrm{~g} \cdot \mathrm{L}-1$ xylitol from $30 \mathrm{~g} \cdot \mathrm{L}^{-1} \mathrm{D}$-arabitol with a yield of $40.8 \%$. On the contrary, the wild-type strain of $G$. oxydans only can produce $7.56 \mathrm{~g} \cdot \mathrm{L}^{-1}$ xylitol with a yield of $25.2 \%$. So the yield was much improved through engineering strain expressed with XDH and GDH genes.

Qi et al [16] cloned the xylitol dehydrogenase gene from G. oxydans CGMCC 1.49 and overexpressed it in E.coli BL21, Approximately $25.10 \mathrm{~g} \cdot \mathrm{L}^{-1}$ xylitol was obtained at 22 $\mathrm{h}$ with a yield of $0.837 \mathrm{~g} / \mathrm{g}$ from $30 \mathrm{~g} \cdot \mathrm{L}^{-1} \mathrm{D}$-arabitol in the batch biotransformation with the recombinant strain BL21- $x d h$, whereas only $8.10 \mathrm{~g} \cdot \mathrm{L}^{-1}$ xylitol was produced in $30 \mathrm{~h}$ by the wild strain with a yield of $0.270 \mathrm{~g} / \mathrm{g}$. Zhou et al[17] cloned a xylitol dehydrogenase gene from G. oxydans and a cofactor regeneration enzyme gene which was a glucose dehydrogenase gene from Bacillus subtilis and co-expressed in E. coli. Approximately $26.91 \mathrm{~g} \cdot \mathrm{L}^{-1}$ xylitol was obtained from around $30 \mathrm{~g} \cdot \mathrm{L}^{-1} \mathrm{D}$-xylulose with a $92 \%$ conversion yield. The xylitol yield of the recombinant strain was more than 3 fold higher compared to that of the $G$. oxydans $\mathrm{NH}-10\left(7.32 \mathrm{~g} \cdot \mathrm{L}^{-1}\right)$. Genetic engineering bacteria constructed by molecular cloning and functional expression of $\mathrm{ArDH}$ and $\mathrm{XDH}$ genes of $G$. oxydans certainly can provide the production of xylitol by biological method with high performance.

\section{V.CONCLUSION}

G. oxydans possess two enzymes enabling the production of xylitol from D-arabitol. The two enzymes were $\mathrm{XDH}$ and $\mathrm{ArDH}$. Since the complexity of two independent catalytic reactions by $\mathrm{XDH}$ and $\mathrm{ArDH}$, there are much more researches should be done to discover novel genes and enzymes which can be used in the process of xylitol production. We found that efficient conversion of D-arabiatol and high yield of xylitol can be achieved by engineering G. oxydans and E.coli respectively. So if we 
carry out more detailed research work on genetic engineering strain, the yield of xylitol will be further improved through biological methods. Meanwhile, in view of the high price of coenzymes (NADH/NAD ${ }^{+}$), the probably method to lighten production cost is to construct engineering strain which can let coenzyme regenerate efficiently.

\section{ACKNOWLEDGMENT}

This work was supported by the National Natural Science Foundation of China (Nos. 31571806 and 21006041) and Project of Jiangsu University (No. 08JDG009) and PAPD.

\section{REFERENCES}

[1] Mäkinen K K. Gastrointestinal Disturbances Associated with the Consumption of Sugar Alcohols with Special Consideration of Xylitol: Scientific Review and Instructions for Dentists and Other Health-Care Professionals [J]. 2016, 2016(6):1-16.

[2] Małgorzata Grembecka. Sugar alcohols - their role in the modern world of sweeteners: a review [J]. European Food Research and Technology, 2015, 241(1):1-14.

[3] Vongsavan K, Surarit R and Rirattanapong P. The combined effect of xylitol and fluoride in varnish on bovine teeth surface microhardness. [J]. Southeast Asian Journal of Tropical Medicine \& Public Health, 2014, 45(2):505-510

[4] Qi X, Luo Y, Wang X, et al. Enhanced D-arabitol production by Zygosaccharomyces rouxii JM-C46: isolation of strains and process of repeated-batch fermentation. [J]. Journal of Industrial Microbiology \& Biotechnology, 2015, 42(5):807-12.

[5] Urrehman S, Mushtaq Z, Zahoor T, A Jamil, and MA Murtaza. Xylitol: a review on bioproduction, application, health benefits, and related safety issues. [J]. Critical Reviews in Food Science and Nutrition, 2015, 55(11):1514-1528.

[6] Onishi H and Suzuki T. Microbial production of xylitol from glucose. [J]. Applied Microbiology, 1969, 18(6):1031-1035.

[7] Suzuki S, Sugiyama M, Mihara Y, K Hashiguchi, and K Yokozeki. Novel enzymatic method for the production of xylitol from D-arabitol by Gluconobacter oxydans.[J]. Bioscience Biotechnology \& Biochemistry, 2002, 66(12):2614-2620.
[8] Qi X H, Luo Y, Zhu J F, et al. Microbial Bioconversion Process of Glucose for the Production of Xylitol [J]. Key Engineering Materials, 2014, 636:149-152.

[9] Hairong Cheng, NingJiang, AnShen, and Youjun Feng. Molecular cloning and functional expression of d-arabitol dehydrogenase gene from Gluconobacter oxydans in Escherichia coli [J]. FEMS Microbiology Letters, 2005, 252(1):35-42.

[10] Adachi O, Fujii Y, Ghaly M F, et al. Membrane-bound Quinoprotein D-Arabitol Dehydrogenase of Gluconobacter suboxydans IFO 3257: A Versatile Enzyme for the Oxidative Fermentation of Various Ketoses [J]. Agricultural and Biological Chemistry, 2001, 65(12):2755-2762.

[11] Xianghui Qi, Jing Lin, Xu Wang, et al. Introduction of two key enzymes: D-arabitol dehydrogenase and xylitol dehydrogenase for microbial production of xylitol. WIT Transactions on Biomedicine and Health, 2014, 18: 313-318.

[12] Sugiyama M, Suzuki S, Tonouchi N, and Yokozeki K. Cloning of the xylitol dehydrogenase gene from Gluconobacter oxydans and improved production of xylitol from D-arabitol. Bioscience, biotechnology, and biochemistry, 2003, 67: 584-591.

[13] Sen X B, Qi X H, Zhu H Y, and Xu H. Cloning, expression and conversion analysis of the xylitol dehydrogenase from Gluconobacter oxydans. China Biotechnology, 2009,29(12): 54-59 .

[14] Li S, Zhang J, Xu H, and Feng X. Improved xylitol production from $D$-arabitol by enhancing the coenzyme regeneration efficiency of the pentose phosphate pathway in Gluconobacter oxydans. [J]. Journal of Agricultural \& Food Chemistry, 2016, 42(10):1043-1047.

[15] Zhang J, Li S, Xu H, et al. Purification of xylitol dehydrogenase and improved production of xylitol by increasing $\mathrm{XDH}$ activity and NADH supply in Gluconobacter oxydans. [J]. Journal of Agricultural \& Food Chemistry, 2013, 61(11):2861-2867.

[16] Qi X H, Zhu J F, Yun J H, et al. Enhanced xylitol production: Expression of xylitol dehydrogenase from Gluconobacter oxydans and mixed culture of resting cell. [J]. Journal of Bioscience \& Bioengineering, 2016, 122(3):257-262.

[17] Peng Z, Sha L, Hong X, X Feng, and P Ouyang. Construction and co-expression of plasmid encoding xylitol dehydrogenase and a cofactor regeneration enzyme for the production of xylitol from D-arabitol [J]. Enzyme \& Microbial Technology, 2012, 51(2):119-124. 